\title{
Editorial: Knowing is Not Enough, We Must Apply
}

\author{
Guillermo Rein*, Department of Mechanical Engineering, Imperial College, \\ London, $U K$
}

Jack Watts has superbly led this journal for several decades, and it is an honour for me to follow his steps and take the stead. My hope is to do nearly as well as he has done. With his help, the support of the Associate Editors, the Editorial Board, Springer staff and especially with the collective efforts of countless reviewers, I look forward a journal that provides and advocates for research and education in fire safety engineering.

Whether science precedes technology or as often observed the inverse order is found, the two of them must communicate and feed to each other if we are to reduce the worldwide burden of fire hazards. This journal wants to bridge the gap. Fire Technology will continue pushing forward the frontiers of knowledge and technology, and help reduce the unworthy obstructions to progress in fire prevention and public safety.

I would like to finish with the wise words of the German writer Goethe (17491832), who said "Knowing is not enough, we must apply. Willing is not enough, we must do".

\footnotetext{
* Correspondence should be addressed to: Guillermo Rein, E-mail: g.rein@imperial.ac.uk
} 